\title{
The Dark Side of Working in a Virtual World: An Investigation of the Relationship between Workplace Isolation and Engagement among Teleworkers
}

\author{
Russell Davis ${ }^{1}$, Steven Cates ${ }^{2}$ \\ ${ }^{1}$ School of Business, Columbia Southern University, Orange Beach, USA \\ ${ }^{2}$ Graduate School of Business, Kaplan University, Fort Lauderdale, USA \\ Email: Russell.Davis@Columbiasouthern.edu, SCates@kaplan.edu
}

Received March 9, 2013; revised April 15, 2013; accepted April 25, 2013

Copyright (C) 2013 Russell Davis, Steven Cates. This is an open access article distributed under the Creative Commons Attribution License, which permits unrestricted use, distribution, and reproduction in any medium, provided the original work is properly cited.

\begin{abstract}
Teleworking is an alternate work arrangement that has transformed the workplace that allows workers to fulfill their job assignment from any location away from the traditional office. Although this work arrangement has been growing in popularity due to various factors such as concerns for the environment, advances in communication technologies, and the globalization of the workforce, there are growing concerns that frequent use of teleworking may cause increase perceptions of feeling isolated [1] Golden, 2001; [2] Marshall, 2007; [3] Golden \& Veiga, 2006; [4] Copper \& Kurland, 2002). Additionally little or no research has been conducted on how feeling isolated influence engagement among teleworkers. The purpose of this quantitative research study is to investigate the relationship between workplace isolation and engagement and to determine to what extent the relationship between workplace isolation and gender among teleworkers. A survey consisting of the Workplace Isolation Scale [2] Marshall, 2007, Employee Engagement Scale [5] DDI, 2005 and demographic factors was used to investigate the relationship between workplace isolation and engagement and used to determine the relationship between workplace isolation and gender among 472 teleworkers. Using a correlational research design, it is found there is a statistically significant relationship between workplace isolation and employee engagement. Workplace isolation scores are shown to have a strong negative correlation with employee engagement scores. A regression analysis utilizing employee engagement as the dependent variable and workplace isolation as the independent variable is conducted. The results indicate statistical significance in that workplace isolation scores predicted employee engagement scores. A two- independent-sample $t$ test is conducted to determine if there is enough evidence to suggest the mean workplace isolation scores are related to gender. The results of the $t$ test are inconclusive. However using descriptive statistics techniques it is discovered respondents who telework 3 to 5 days a week have lower workplace isolation means scores than those who teleworked 1, 2 and 4 days a week. Leaders of organizations can use the results of this study to assist in the development of teleworking engagement strategies that not only target reducing workplace isolation perceptions to enhance engagement for teleworkers, but also to address possible issues related to increased perceptions of isolation across gender.
\end{abstract}

Keywords: Teleworking; Virtual Employees; Workplace Isolation; Depression; Employee Engagement

\section{Introduction}

Recent advances in information technologies have made it possible for organizational workers to become untethered from their traditional office setting [6] Golden, Veiga, \& Dino, 2008. This virtualization of contemporary organizations has evolved out of necessity as firms compete for workers globally and advances in information technology provide the means [7] World at Work,
2012. It is estimated that by 2016 nearly 90 million selfemployed and non-self-employed US workers will work from home or from a remote location at least 2 to 3 days a week [8] Lister \& Harnish, 2011. With the enactment of two key bills, the Telework Enactment Act (S. 707) and Telework Improvement Act (H.R. 1722), the US Federal Government estimates by 2016 the 90 million teleworkers growth estimation is a conservative number 
[8] Lister \& Harnish, 2011.

\section{Scope of the Problem}

Given these forecasts for huge growth in this employment sector there is a dark side for those working in this field. The issues of workplace isolation and lack of employee engagement in the organization are seen as major and critical problems that employers will have to deal with.

\section{Literature Review}

Investigating the relationship between workplace isolation and engagement among teleworkers is based on future recommendations and gaps in the literature that are found from previous research across various well publicized research studies and published manuscripts

[9] Webster-Trotman, 2010; [10] Hester-Smith, 2011; [11] O'Neil, Hambley, Greidanus, MacDonnell \& Kline 2009; [6] Golden, Veiga and Dino, 2008; [2] Marshall, Michaels \& Mulki 2007; [4] Cooper \& Kurland 2002).

[6] Golden, Veiga and Dino (2008) posited isolation felt by remote workers has not been widely researched, although more generalized notations have been studied. In nearly all of the previous research authors make references to claims that telework is an alternative work mode that increases job satisfaction is unexplained and unsubstantiated. Specifically, [9] Webster-Trotman (2010) found there is no significant relationship between teleworking and job satisfaction. However in the research conducted by [10] Hester-Smith (2010) findings indicated there is a significant relationship between job satisfaction and perceptions of workplace isolation. [11] O'Neil, Hambley, Greidanus, MacDonnell \& Kline (2009) posit that despite all the claimed potential advantages of teleworking such as reducing the time, energy, expenses for commuting, and greater autonomy, independence, and increased job satisfaction, teleworking is not for the masses. [6] Golden, Veiga and Dino (2008) posited that further research is warranted due to the limited existing qualitative studies conducted. [1] Golden 2001 provides research that finds support from that of [4] Cooper \& Kurland (2002) in teleworking can create an environment where increased perceptions of isolation are derived from thwarted social interaction that is a potential outcome from teleworking. [4] Cooper and Kurland (2002) posit that a perception of isolation among teleworkers is linked to the lack of personal interaction, limited informal learning, and mentoring. In the research conducted references claiming telework increased job satisfaction is unfounded. In all of the research recommendations to investigate whether teleworking frequency influences workplace isolation, job satisfaction and engagement among teleworkers is needed.

\section{Objectives of the Study}

This research investigates the relationship between workplace isolation and engagement among teleworkers and seeks to answer whether there is a relationship between workplace isolation and gender.

\section{Hypotheses}

Given the Research Question of is there a relationship between workplace isolation and engagement and to what extent the relationship between workplace isolation and gender among teleworkers in this research study the following Hypotheses are tested:

H1o: There is no statistically significant relationship between workplace isolation and engagement among teleworkers.

H1a: There is a statistically significant relationship between workplace isolation and engagement among teleworkers.

$\mathrm{H} 2 \mathrm{o}$ : There is no statistically significant relationship between gender and workplace isolation among teleworkers.

H2a: There is a statistically significant relationship between gender and workplace isolation among teleworkers.

\section{Methodology}

This study involves a correlational design that investigates the relationship between workplace isolation and engagement among teleworker and investigates whether there is a relationship between workplace isolation and gender. In this study the independent variable is workplace isolation and the dependent variable is engagement. Control variables such as age, gender, education, ethnicity, time working with the firm, telework frequency and the collaboration tools used in a teleworking environment is also used. Statistical procedures are used to control such variables in order to determine the influence the independent variable has on the dependent variable. Correlational analysis is used to investigate the relationship between workplace isolation scores and engagement scores among 472 teleworkers. Regression analysis is conducted to determine whether there is a predictive relationship between the variables. The regression analysis is significant.

A major expectation for this research is to test [12] Maslow's (1943) Hierarchy of Needs theory as it relates to workplace isolation and engagement. Workplace isolation is assessed against Maslow's Level Three Hierarchy of Needs. The expectation is that social relationships are what directly affect human motivation in a teleworker environment. As indicated by the outcome of this study it is suggested that if social interaction is thwarted, percep- 
tions of isolation will occur, which impact productivity, quality, and engagement among teleworkers. Another major expectation for this research comes from the testing of [12] Maslow's (1943) Hierarchy of Needs theory as it relates to workplace isolation and engagement. Workplace isolation is assessed against Maslow's Level Three needs. It is expected to show that social relationships are what drive human motivation in a teleworker environment and that if the social need is thwarted, perceptions of isolation will emerge, which can have a negative influence on employee productivity, work quality, and engagement among teleworkers.

[13] Creswell (2009) posited that control variables used in a quantitative study play a vital role because these variables potentially influence the dependent variable (engagement). Additionally, statistical procedures are used to control such variables in order to determine the influence the independent variable has the on the dependent variable. [14] Leedy \& Ormrod (2009) posit that a correlational design is a type of descriptive research design that involves investigating possible relationships among variables. This study consists of a correlational and regression analysis that analyzes the survey data that assists in the support or rejection of this study's' hypotheses. According to [14] Leedy \& Ormrod (2009) and [15] Simon (2006) correlational studies are a valid statistical method used to investigate variables in natural environment and do not include researcher imposed treatment.

The population for this study is teleworkers and a sample population is identified from teleworkers. Using $\mathrm{G}^{*}$ Power 3.1.3 software, the adequate sample size is defined as 262 participants (includes effect size $=0.05, \alpha$ error of $=0.05$, Power $(1-\beta)=0.95)$ [16] Faul, Erdfelder, \& Lang, 2007.

A research announcement informed the participants about the research and provided the means for participants to consent to participate in the research. Electronic mail was used as the delivery vehicle for the notifications and access to the research survey link.

The survey was released to Zoomerang.com for distribution. The survey was left open for a 2 week period. At the closing of the survey, participant data was gathered by Zoomerang.com and downloaded. After the download, the data was verified, backed up and then purged off Zoomerang.com.

The electronic survey contained questions from two academic reliable scales, Workplace Isolation Scale [2] Marshal et al., 2007 and Employee Engagement Scale [5] DDI, 2005. These two scales have been used in previous research and are considered reliable and valid scales that test for perceptions related to worker isolation and engagement. Both of these scales use a 7-point Likert scale. Permission to use the Workplace Isolation and Employee
Engagement instruments were provided via email.

[2] Marshall et al., 2007 developed the Workplace Isolation Scale which measures two facets of isolation; the two facets are colleague and company isolation. Workplace isolation is the result from workers' perception of a lack of availability of support from colleagues, missed opportunities to interact with colleagues and the company social network and not feeling part of the overall organization group. Prior research suggests critical factors in the success of organizational members' stem from the availability of support from colleagues [1] Golden et al., 2008; [2] Marshall, et al., (2007). [1] Golden et al., (2008) posited that perceptions of a lack of colleague support can lead to negative feelings among teleworkers.

Survey data downloaded was imported to IBM SPSS Statistics software version 20. The survey data consists of demographic data (age, gender, ethnicity, education level, position with the company, tenure with the company, frequency of teleworking, and the type of collaboration tool used mostly in a telework setting). The demographic data remained intact with the survey data. The Workplace Isolation and Employee Engagement scales consisted of a 7 point Likert scale anchored with 1 equaling "very strongly disagree" to 7 equaling "very strongly agree". Per the authors' recommendation related to the Workplace Isolation instrument and approval to use the instrument, surveys scores were reversed before computing descriptive and correlational statistics (Marshall et al., 2007). According to [17] Trochim 2000 a 7 point Likert scale provides the means to capture a higher degree of attitudinal data. IBM SPSS Statistics software version 20 will be used to analyze the survey data.

Descriptive statistics are used to describe demographic factors (means, standard deviation, median, and mode. A Pearson product-movement correlation assessment is used to examine whether relationships exist between workplace isolation scores and engagement scores. Pearson product-movement correlation coefficient is used to measure the degree of association between two or more variables. The Pearson correlation coefficients range from -1 to +1 with values close to -1 indicating a strong negative correlation and with +1 indicating strong positive correlation, and values close to zero indicating a weak or no association between the variables [18] Keller, 2006. Partial correlations are used to control for spurious correlations. Regression analysis is used to examine whether engagement (the dependent variable) scores can be predicted by workplace isolation (the independent variables) scores. Additionally a two-independent-samples $\mathrm{t}$ test is used to determine if workplace isolation means scores are related across gender. For this study a p-value of .05 or less was used to suggest if there was enough evidence to accept the research hypothesis and to 
deem the statistical analysis significant. According to [18] Keller (2006), "a p-value of a test is the probability of observing a test statistic that is at least as extreme as the one computed, given that the null hypothesis is true" (p. 353).

The data collected from 472 respondents via an online survey were imported to IBM SPSS software. Descriptive statistics were performed to identify demographic characteristics. Close to $60 \%$ of the respondents were female, with about $40 \%$ male. Thirty-six percent of the respondents held bachelor degrees while $29.4 \%$ had earned master degrees. The age group of the respondents was mostly $40-49$ years of age of which $56.6 \%$ were females and $51.3 \%$ were males. Fifty-five percent of females and $54.9 \%$ males reported working in a teleworking mode 5 days a week. The information technology used mostly was electronic mail (66\%). Respondents reported that $36.9 \%$ of the job function held was nonmanagement technical or professional while $24.6 \%$ being first line management. Fifty-nine percent of those who teleworked 5 days week were in the job functions of non-management technical or professional positions.

A Pearson product-movement analysis was conducted to determine whether a relationship existed between workplace isolation mean scores and engagement mean scores. The result of the analysis was significant showing a strong negative correlation, $r=-0.954, p=0.000$. A regression analysis was performed to determine whether workplace isolation mean scores predict engagement mean scores and the results of that analysis was significant, $F(1,8)=80.9, p=0.000$. A regression analysis was performed to determine whether engagement mean scores predict workplace isolation mean scores and the results of that analysis was significant. Therefore H1a finds great support and the Null must be rejected.

Descriptive statistics and a two-independent-sample $t$ test were conducted to determine whether there is a relationship between workplace isolation scores and gender. Descriptive statistics for male and female displayed a difference in overall workplace isolation mean scores. Although descriptive statistics suggests there is a difference in workplace isolation means scores the two-independent-samples $t$ test resulted in the test not being statistically significant $(M=0.093, S D=0.200)$, conditions; $\mathrm{t}(9)=1.46, p=0.117)$. Overall descriptive statistics showed workplace isolation mean scores for male were lower compared to females. Males who teleworked 3 days and 5 days per week had lower scores as compared to females who teleworked the same duration per week. Both gender showed lower workplace isolation scores for 5 days of teleworking as compared to 3 days of teleworking. Given these results $\mathrm{H} 2 \mathrm{a}$ must be rejected and the Null is supported and accepted.

These findings also support and confirm the theoretical construct of [12] Mazlow's Hierarchy of Needs, 1943that posits that humans need to have a sense of belonging as a basic need to be met.

\section{Implications for Management}

Based on forecasts that 90 million employees will be engaged in this field of work in the near future it is very important for managers to understand the downsides of utilizing this form of worker environment. This study provides evidence that employees who work in an external environment will have difficulties in handling the lack of human contact and will feel disconnected from the organization employing them.

Managers need to consider methods of daily contact with these employees so the perception of isolation is diminished. Managers may want to consider limiting the amount of external work of each employee in order to give employees a greater sense of belonging.

Managers may want to study [12] Mazlow's Hierarchy of Needs, 1943 in order to gain a better sense of understanding the human need for contact and belonging as a way to engage and motivate employees

\section{Implications for Future Research}

The opportunity to analyze all of the demographic variables will shed greater insight on further factors that might influence engagement and or determine issues surrounding isolation in working in a virtual environment. Tests of association in relation to teleworking frequency, gender, technology used, age, education, tenure with the company may produce some insight that will help the research field further understand how demographic variables can be influenced in relation to perceptions of isolation.

\section{Conclusion}

The investigation of the relationship between workplace isolation and engagement among teleworkers is significant. Little or no research has been conducted on these variables until this study. This research has provided results that indicate there are critical issues between workplace isolation and employee engagement among those who work in a virtual environment. This will be a significant area of study as more organizations choose to engage employees in virtual jobs.

\section{REFERENCES}

[1] T. D. Golden, "Telecommuting Optimization: An Investigation of Influential Factors during Technology-Reliant Interaction," Dissertation Abstracts International, Vol. 62, No. 9, 2001, p. 3106A.

[2] G. W. Marshall, C. E. Michaels and J. P. Mulki, "Work- 
place Isolation: Exploring the Construct and Its Measures," Psychology \& Marketing, Vol. 24, No. 3, 2007, pp. 195-223. doi:10.1002/mar.20158

[3] T. D. Golden and J. F. Veiga, "The Impact of Extent of Telecommuting on Job Satisfaction: Resolving Inconsistent Findings," Journal of Management, Vol. 31, No. 2, 2006, pp. 301-318. doi:10.1177/0149206304271768

[4] C. D. Cooper and N. B. Kurland, "Telecommuting, Professional Isolation, and Worker Development in Public and Private Organizations," Journal of Organizational Behavior, Vol. 23, No. 4, 2002, pp. 511-532. doi:10.1002/job.145

[5] Development Dimension International DDI, "E3: A Measure of Employee Engagement," Author, Bridgeville, 2005.

[6] T. D. Golden, J. F. Veiga and R. N. Dino, "The Impact of Professional Isolation on Teleworker Job Performance and Turnover Intentions: Does Time Spent Teleworking, Interacting Face-to-Face, or Having Access to Communication-Enhancing Technology Matter?" Journal of Applied Psychology, Vol. 93, No. 6, 2008, pp. 1412-1421. doi: $10.1037 / \mathrm{a} 0012722$

[7] WorldatWork, "Telework Trend Lines 2012: A Survey Brief by WorldatWork," 2012. http://www.worldatwork.org/waw/adimLink?id=53034

[8] K. Lister and T. Harnish, "The State of Teleworking in the US: How Individuals, Businesses, and Government Benefit," Teleworker Research Network, 2012. http://www.workshifting.com/downloads/downloads/Tele work-Trends-US.pdf

[9] S. P. Webster-Trotman, "A Correlational Study of Telework Frequency, Information Communication Technology, and Job Satisfaction of Home-Based Teleworkers," Dissertations and Theses, Walden University, Minneapolis, 2010.

http://search.proquest.com/docview/305228279?accounti $\mathrm{d}=33337$

[10] V. Hester-Smith, "An Investigation of the Relationship between Job Satisfaction and Isolation among Telecommuters," Dissertations and Theses, Capella University, Minneapolis, 2011.

http://search.proquest.com/docview/305240371?accounti $\mathrm{d}=33337$

[11] A. O’Neil, T. Hambley, A. L. Greidanus, S. N. MacDonnell, R. and J. B. T. Kline, "Predicting Teleworker Success: An Exploration of Personality, Motivation, + Situational and Job Characteristics," New Technology, Work and Employment Journal, Vol. 24, No. 2, 2009, pp. 144162. doi:10.1111/j.1468-005X.2009.00225.X

[12] A. Maslow, "A Theory of Human Motivation," Psychological Review, Vol. 50, No. 4, 1943, pp. 250-329. doi: $10.1037 / \mathrm{h} 0054346$

[13] J. W. Creswell, "Research Design: Qualitative, Quantitative, and Mixed Methods Approaches," 3rd Edition, Sage, Loa Angels, 2009.

[14] P. D. Leedy and J. E. Ormrod, "Practical Research: Planning and Design," 9th Edition, Pearson, Boston, 2010.

[15] M. K. Simon, "Dissertation and Scholarly Research: A Practical Guide to Start and Complete Your Dissertation, Thesis, or Formal Research Project," Kendal/Hunt, Dubuque, 2006.

[16] F. Faul, E. Erdfelder, A. G. Lang and A. Buchner, "G*Power 3: A flexible Statistical Power Analysis Program for the Social, Behavioral, and Biomedical Sciences," Behavior Research Methods, Vol. 39, No. 2, 2007, pp. 175-195. doi:10.3758/BF03193146

[17] W. Trochim, "The Research Methods Knowledge Base," 2nd Edition, Atomic Dog Publishing, Cincinnati, 2000.

[18] G. Keller, "Statistics for Management and Economics," 8th Edition, South-Western, Mason, 2006. 